\title{
APLICAÇÃO DA TÉCNICA PPP PARA A OBTENÇÃO DO POSICIONAMENTO NA CABOTAGEM NO BRASIL: ESTUDO DE CASO
}

\author{
PPP Technical Application for Positioning in Brazil Cabotage: A Case Study
}

\author{
Flávio Guilherme Vaz de Almeida Filho ${ }^{1}$ \\ Hugo Tsugunobu Yoshida Yoshizaki² \\ Cláudio Barbieri da Cunha ${ }^{1}$ \\ Edvaldo Simões da Fonseca Júnior ${ }^{1}$ \\ André Shigueo Kiyota ${ }^{2}$
}

\begin{abstract}
1 Departamento de Eng. de Transportes - Escola Politécnica - PTR-EPUSP.Av. Prof. Almeida Prado, trav.2, no 83 - São Paulo - SP CEP 05508-070, Brasil

2 Pós Graduação em Eng. Sistemas Logísticos - Escola Politécnica - USP.Av. Prof. Almeida Prado, trav.2, no 128 - São Paulo - SP CEP 05508-070, Brasil
\end{abstract}

\section{Resumo}

Este artigo apresenta uma metodologia de instrumentação e processamento de dados GPS para a obtenção de posicionamento preciso para cabotagem no Brasil. Para isso, um navio porta contêineres foi equipado com um par de receptores GPS (L1/L2) para o rastreio das observáveis no trajeto Santos (SP) - Suape (PE); e seu pós-processamento por Posicionamento por Ponto Preciso (PPP) cinemático. A precisão obtida foi $\sim 23,1 \mathrm{~cm}$. Desprezando os primeiros 60 minutos de rastreio a precisão foi de $8,0 \mathrm{~cm}$. O coeficiente de correlação nas direções dos receptores foi de $R^{2}=0,922$. Assim, foi possível obter dados precisos sobre a trajetória da embarcação, sua velocidade, aceleração, deriva e amplitude das inclinações. Esta instrumentação é uma etapa de um projeto que visa minimizar as emissões de gases causadores do efeito estufa (GEE) no transporte intermodal de cargas. As informações precisas da dinâmica da embarcação poderão servir como parâmetros de ajuste em modelos de emissão existentes.

Palavras-Chave: GPS. Cabotagem. PPP.

\begin{abstract}
:
This paper presents a methodology for GPS instrumentation and data post-processing for precise vessel tracks positioning along the Brazilian coast. In order to reach this aim, a container vessel was equipped with a pair of GPS receivers (L1/L2) for GPS data collection in sea path, from Santos (SP) to Suape (PE). The data were processed using Precise Point Positioning (PPP) methodology. The coordinates accuracy obtained for this path was about $23.1 \mathrm{~cm}$. If the first 60 minutes of data were not used, the accuracy improved to approximately $8.0 \mathrm{~cm}$. The correlation coefficient estimated between the receivers bearing was $R^{2}=0.922$. Therefore, it was possible to obtain accurate information about the vessel trajectory and its speed, acceleration, relative drift
\end{abstract}


and the tilt amplitude. This information will be utilized as input parameters of the greenhouse gas emissions (GHG) models previously developed.

Keywords: GPS. PPP. Cabotage.

\section{Introdução}

Este artigo tem por objetivo apresentar uma metodologia detalhada para a instrumentação de grandes embarcações porta contêineres operando em cabotagem com receptores de posicionamento preciso por satélites artificiais da constelação Global Navigation Satellite System (GNSS), em especial o Global Positioning System (GPS); e o respectivo procedimento para o pós-processamento das observáveis obtidas no percurso realizado.

O transporte marítimo de cabotagem pode ser definido como o transporte entre dois portos de um mesmo país, envolvendo o fluxo de cargas entre entes nacionais. O Brasil possui uma extensão costeira de $7.408 \mathrm{~km}$ com 34 portos ao longo da costa (CNT, 2015) e um sistema portuário em franco processo de modernização e expansão, o que faz a cabotagem uma alternativa logística com grande potencial para seus usuários.

A utilização de contêineres no transporte marítimo de cabotagem tem crescido $15 \%$ de forma constante nos últimos dez anos seguindo o Compound Annual Growth Rate (CAGR). A Tabela 1 apresenta o crescimento da movimentação de contêineres de 2001 a 2010, o peso movimentado em toneladas e em Twenty Equivalent Units (TEUs). Atualmente, a cabotagem nacional conta com 24 navios operando de forma dedicada.

Tabela 1: Movimentação de Contêineres na Cabotagem (ANTAQ, 2011)

\begin{tabular}{c|c|c|c}
\hline Ano & $\begin{array}{c}\text { Quantidade } \\
\text { (Cheios+Vazios) }\end{array}$ & $\begin{array}{c}\text { Peso } \\
(1.000 \mathrm{t})\end{array}$ & $\begin{array}{c}\text { 1.000 TEUs } \\
\text { (cheios) }\end{array}$ \\
\hline 2001 & 201.356 & 2.159 & 116 \\
2002 & 258.909 & 2.988 & 160 \\
2003 & 280.463 & 3.229 & 168 \\
2004 & 235.743 & 3.699 & 190 \\
2005 & 263.158 & 3.503 & 210 \\
2006 & 318.299 & 4.320 & 247 \\
2007 & 315.678 & 4.164 & 219 \\
2008 & 410.967 & 5.616 & 378 \\
2009 & 377.973 & 4.697 & 294 \\
2010 & 350.290 & 5.199 & 321 \\
\hline
\end{tabular}

O eixo Sudeste-Nordeste, analisado no presente trabalho, é um dos principais corredores do transporte de cabotagem em termos de volume de movimentação anual de cargas, conectando dois importantes pólos consumidores e produtivos. Assim, a partir de escalas semanais e regulares de navios nos portos de Suape (PE) e Santos (SP), pretendendo-se atender a demanda desses mercados num prazo médio de três dias de navegação.

A popularização dos sistemas de informações geográficas (SIG) aliados à crescente facilidade de acesso às técnicas de posicionamento de alta precisão a partir de satélites artificiais, como o 
GPS, tem permitido diferentes soluções para a caracterização geográfica das rotas utilizadas nas principais vias de transporte de cargas.

O posicionamento de alta precisão a partir da técnica de rastreio de satélites artificiais do sistema GPS foi desenvolvido pelo Departamento de Defesa Norte Americano (DoD) e disponibilizado para usuários civis no final do século XX. Esta técnica de posicionamento, hoje já bastante popular, é baseada na estimativa das distâncias do receptor aos satélites pertencentes a uma constelação composta por pelo menos 24 veículos espaciais em órbita a aproximadamente $20.200 \mathrm{~km}$ de altitude. Estimada, pela fase da onda portadora e outras componentes, a distância de cada satélite ao receptor e sua posição na órbita, por um processo de triangulação, é possível determinar com acurácia estimável a posição da antena do receptor sobre a superfície terrestre. Este sistema tem se tornado mais acessível na medida da popularização e redução do preço dos equipamentos receptores geodésicos de dupla frequência (L1/L2). Diferentes técnicas de pósprocessamento podem ser aplicadas para melhorar a acurácia obtida.

Aliado a isto, o desenvolvimento de métodos de processamento dos dados rastreados por estes receptores são oferecidas gratuitamente via internet como, por exemplo, o serviço PPP cinemático pós-processado oferecido pelo Instituto Brasileiro de Geografia e Estatística (IBGE, 2015), possibilitando obter coordenadas geodésicas precisas a um custo operacional mais baixo que anteriormente. Isto minimiza a necessidade de aquisição de computadores de alto desempenho, software dedicado e configurações muito elaboradas. Este serviço de posicionamento faz uso do aplicativo de processamento CSRS-PPP desenvolvido pelo Geodetic Survey Division of Natural Resources of Canada (NRCan, 2015). Para este artigo não houve a necessidade de se obter as coordenadas em tempo-real.

Em alguns trechos do percurso da embarcação, a grande distância às estações da rede brasileira de monitoramento contínuo (RBMC, 2015) do IBGE, conforme apresentado na Tabela 2 e na Figura 1, piora (degrada) a acurácia obtida no posicionamento por dupla diferença de fase. Segundo Geng et al. (2010), para linhas de base longas, maiores que $200 \mathrm{~km}$, o erro acumulado aproxima-se daquele do uso da técnica de pós-processamento PPP (Zumberge et al., 1997) (Kouba et al., 2001), no qual nenhuma estação em terra com coordenadas conhecidas é usada para o estabelecimento de uma base de referência. Segundo o Manual do Usuário Posicionamento Por Ponto Preciso (IBGE, 2014) a denominação PPP "refere-se à obtenção da posição de uma estação utilizando as observáveis fase da onda portadora coletadas por receptores de duas freqüências (L1/L2) e em conjunto com os produtos do International GNSS Service" (IGS, 2012) (Moore e Neilan, 2005).

Outro empecilho causado pela grande distância à costa é a impossibilidade de dispor de canais de telecomunicação terrestre para aplicar correções diferenciais em tempo real no posicionamento como, por exemplo, a técnica Real Time Kinematic (RTK). Segundo Cintra et al.(2011), o comprimento de linhas de base de até $2.700 \mathrm{~km}$ causam um impacto na acurácia do posicionamento planimétrico de até $20 \mathrm{~cm}$. Deste modo, condicionado a existência destes canais de comunicação, esta técnica poderia atender aos requisitos de acurácia para este estudo.

A precisão obtida entre processamento por dupla diferença de fase com o software científico Bernese v.5.0 (AIUB, 2007) e em PPP para distâncias entre $440 \mathrm{~km}$ e $550 \mathrm{~km}$ apresentam erros em torno de 3,3 mm para o leste, 4,8 $\mathrm{mm}$ para o norte e 11,8 $\mathrm{mm}$ na altura (Ebner e Featherstone, 2008). Por outro lado, linhas de até $500 \mathrm{~km}$ de comprimentos processadas em PPP não implicam grandes erros na deriva do relógio do receptor em relação ao do satélite, como apresentado no trabalho de Geng et al. (2010). 


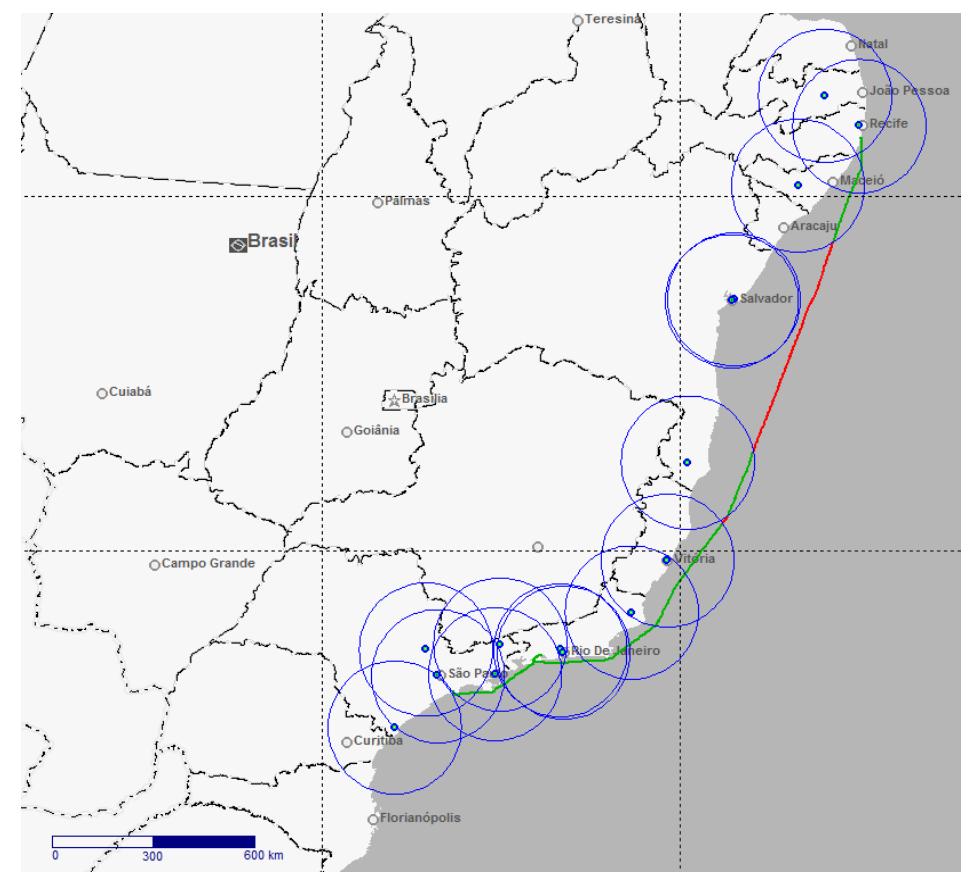

Figura 1: Estações RBMC com raio de 200 km; Trajeto da embarcação com distância <200 km a uma estação (verde) e >200 km (vermelho).

Tabela 2: Distância mínima do receptor à estação RBMC:

\begin{tabular}{c|l|l|l|c}
\hline $\begin{array}{c}\text { Código } \\
\text { Estacãao }\end{array}$ & \multicolumn{1}{|c|}{ Município } & Latitude $\left(^{\circ}\right)$ & Longitude $\left({ }^{\circ}\right)$ & $\begin{array}{c}\text { Distância } \\
\text { Mínima (km) }\end{array}$ \\
\hline ALAR & Arapiraca (AL) & $-9,74921285$ & $-36,65341988$ & 155,64 \\
BATF & Teixeira de Freitas (BA) & $-17,55482316$ & $-39,74334457$ & 167,80 \\
CEFE & Vitória (ES) & $-20,31073915$ & $-40,31945488$ & 64,01 \\
CHPI & Cachoeira Paulista (SP) & $-22,68709877$ & $-44,98515830$ & 100,39 \\
NEIA & Cananéia (SP) & $-25,02022204$ & $-47,92496852$ & 194,08 \\
ONRJ & Rio de Janeiro (RJ) & $-22,89565466$ & $-43,22433157$ & 31,05 \\
PBCG & Campina Grande (PB) & $-7,21367286$ & $-35,90713769$ & 166,19 \\
POLI & São Paulo (SP) & $-23,55560838$ & $-46,73031199$ & 63,16 \\
RECF & Recife (PE) & $-8,05095702$ & $-34,95151641$ & 34,69 \\
RIOD & Rio de Janeiro (RJ) & $-22,81779790$ & $-43,30627659$ & 40,28 \\
RJCG & C. dos Goytacazes (RJ) & $-21,76481312$ & $-41,32615574$ & 73,48 \\
SAVO & Salvador(BA) & $-12,93922177$ & $-38,43225371$ & 217,45 \\
SPCA & Campinas (SP) & $-22,81623975$ & $-47,06269336$ & 150,52 \\
SSA1 & Salvador(BA) & $-12,97513298$ & $-38,51648463$ & 225,05 \\
UBA1 & Ubatuba(SP) & $-23,50013684$ & $-45,11890148$ & 37,19 \\
\hline
\end{tabular}

Assim, a facilidade de acesso destes serviços viabiliza, sob diferentes aspectos - técnicos e econômicos - o monitoramento e rastreio de veículos de carga com precisão na ordem de grandeza do decímetro ou melhor. Além disso, o uso do PPP para o pós-processamento das observáveis GPS pode ser considerado como uma solução viável para o posicionamento preciso de embarcações ao longo da rota, como o percorrido para este trabalho.

A partir da obtenção de coordenadas acuradas, grandezas físicas, como posição, velocidade, aceleração, trajetória, ângulo de deriva, inclinação e balanço, podem ser estimados. A variação na dinâmica da embarcação implica em um consumo energético e de combustível no percurso e, consequentemente, na emissão de gases causadores do efeito estufa (GEE). Alguns modelos de cálculo de emissões, como apresentados e discutidos por Demir et al. (2011), podem apresentar 
estimativas deste consumo e o conhecimento preciso da dinâmica da embarcação pode ajudar na calibração destes modelos à realidade Brasileira.

\section{Metodologia de pesquisa}

\subsection{Conjunto de dados}

\subsubsection{Equipamentos GPS}

Para o levantamento das observáveis GPS ao longo do percurso foram utilizados os seguintes equipamentos:

02 Receptores GPS/GNSS Topcon Legacy (L1/L2); 02 antenas Topcon Choke Ring com capa protetora de plástico; 04 baterias principais de $12 \mathrm{v}$ e $2.3 \mathrm{AH} ; 02$ baterias secundárias de $12 \mathrm{~V}$ e $800 \mathrm{mAH} ; 01$ cabo de transferência de dados do receptor para computador PC; 02 carregadores de bateria modelo HPX10; 02 cabos RV2 coaxial 10m; 02 cabos RV3 de alimentação das baterias principais; 02 cabos RV4 de alimentação das baterias secundárias; 02 Espaçadores metálicos sextavados com $12 \mathrm{~cm}$ de altura.

\subsubsection{Especificações técnicas do receptor:}

A Tabela 3 apresenta as principais características técnicas do receptor.

Tabela 3: Principais características técnicas do Receptor

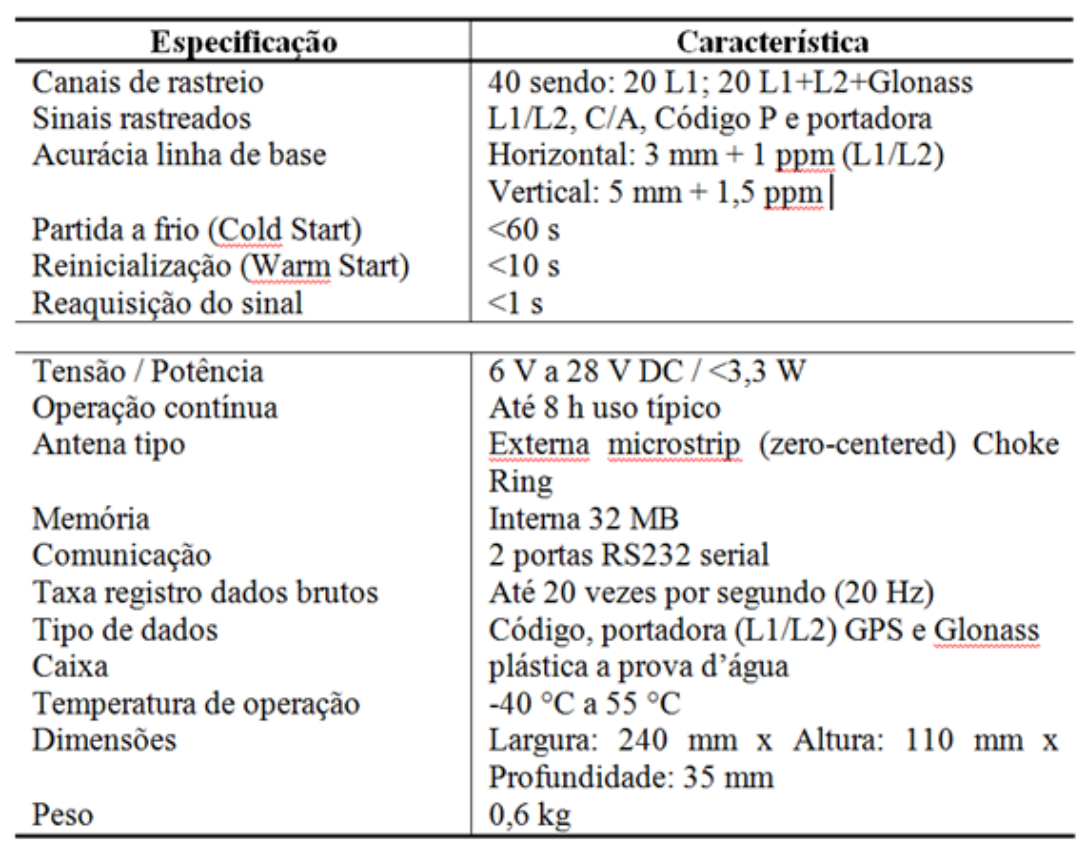

Bol. Ciênc. Geod., sec. Artigos, Curitiba, v. 22, no3, p.526-541, jul-set, 2016 


\subsubsection{Especificações técnicas da embarcação:}

A Tabela 4 apresenta as principais características técnicas e construtivas da embarcação.

Tabela 4: Principais características técnicas e construtivas da embarcação

\begin{tabular}{l|l}
\hline \multicolumn{1}{c|}{ Especificação } & Característica \\
\hline Ano de construção (BUILT) & 1993 \\
Capacidade nominal em TEUs (Twenty Equivalent Units) & 2.161 \\
Capacidade média de carregamento com peso médio de 14t por TEU & 1.850 \\
Capacidade total (Dead-Weight) & $32.984 \mathrm{t}$ \\
Número de tomadas para contêineres refrigerados & 254 \\
Comprimento da embarcação (LOA) & $200,23 \mathrm{~m}$ \\
Boca do navio - largura frontal (Breadth) & $32,20 \mathrm{~m}$ \\
Calado necessário (Draft) & $12,02 \mathrm{~m}$ \\
Velocidade em nós & $18,5 \mathrm{kts}$ \\
\hline
\end{tabular}

\subsubsection{Instalação}

A instalação dos receptores GPS descritos anteriormente foi realizada sobre os painéis externos de comando do navio, localizados sobre o passadiço externo, como na Figura 2. O receptor instalado ao lado esquerdo da cabine central para quem observa da popa para a proa (bombordo) será denominado neste trabalho como GPS 1; e o receptor ao lado direito (estibordo) denominado GPS2. Estes painéis são utilizados pelo operador de manobras de aproximação da embarcação aos portos, conhecido como prático. Para proteção das intempéries, principalmente à chuva e ao vento, estes painéis são recobertos por uma capa metálica basculante integrada ao conjunto, como apresentado na Figura 3. Os receptores foram posicionados sobre os referidos painéis juntamente com duas baterias para cada receptor. $\mathrm{O}$ uso de baterias foi necessário devido à impossibilidade de se obter uma fonte de energia elétrica diretamente dos painéis externos. A bateria principal tinha por objetivo manter o receptor ligado em operação por até 8 horas. A bateria secundária tinha como função manter o aparelho ligado durante a troca da bateria principal, de forma a evitar interrupção no rastreio. As baterias principais foram recarregadas em ciclos de 8 horas alternadamente às baterias em uso no receptor. As baterias secundárias foram recarregadas a cada duas trocas da bateria principal. As antenas utilizadas nesta instalação foram do tipo Choke Ring para minimizar a ocorrência de multi-caminhamento de sinais devido à reflexão na superfície da água. 


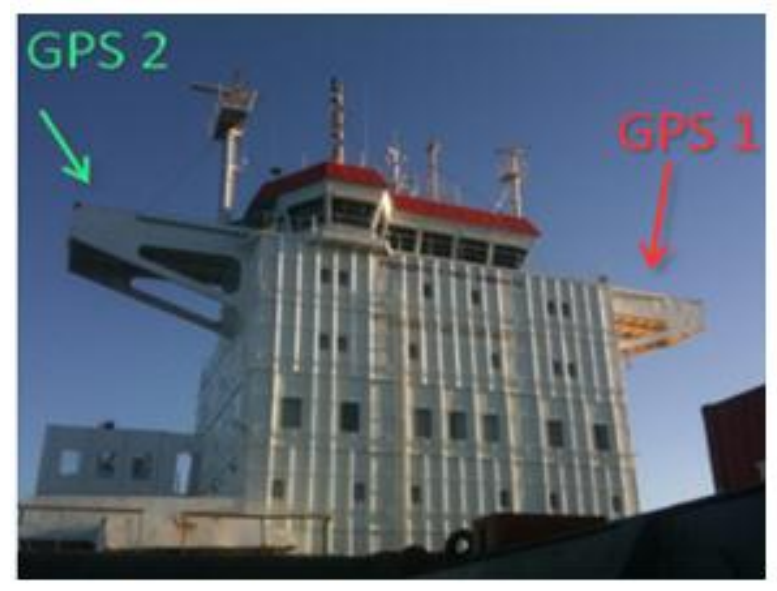

Figura 2: Passadiço sobre o qual foram instalados os receptores
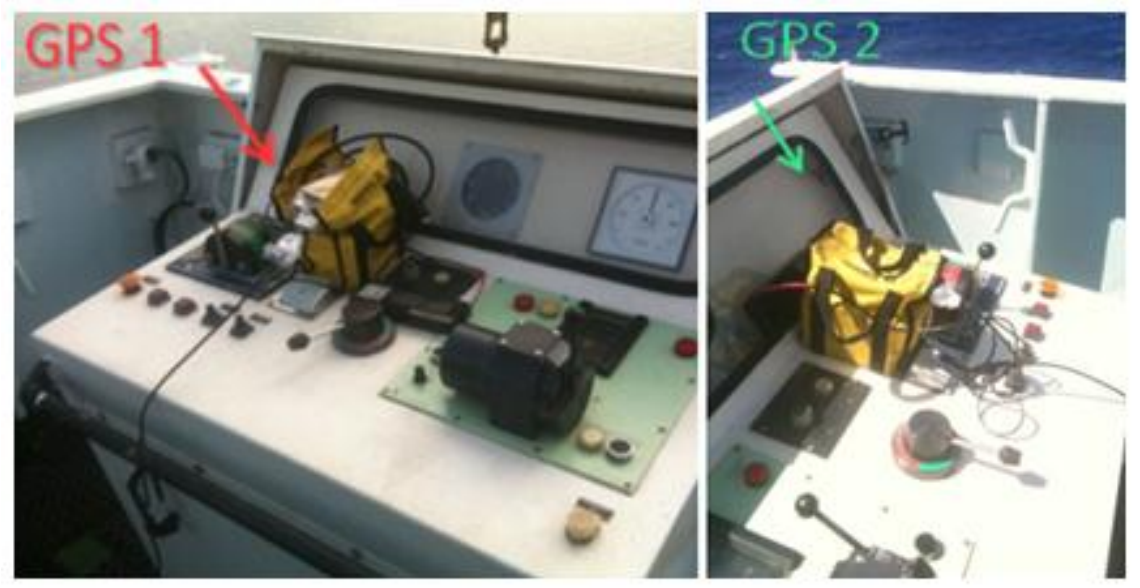

Figura 3: Painéis externos de comando (esquerda e direita) sobre os quais foram instalados os receptores

A instalação das antenas foi sobre o guarda-corpo do passadiço principal, fixadas diretamente na estrutura metálica através de um orifício na estrutura. Foi utilizado um espaçador sextavado com $12 \mathrm{~cm}$ de altura para evitar o contato da parte inferior da antena com o guarda-corpo. Tal espaçador era dotado de um orifício com rosca na parte inferior para fixação do mesmo e um pino com rosca na parte superior para fixação da antena, como apresentado na Figura 4.

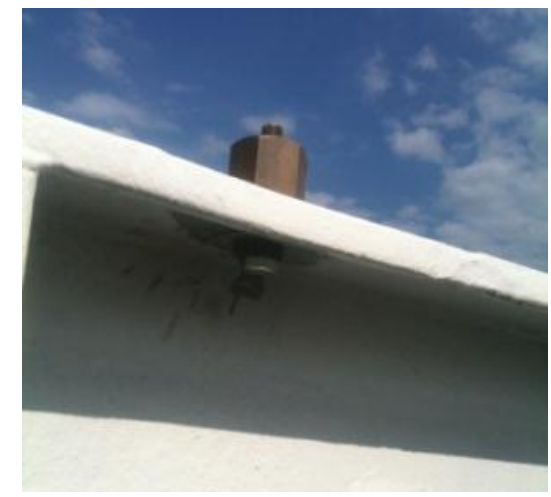

Figura 4: Suporte metálico para instalação da antena ao guarda-corpo do passadiço 


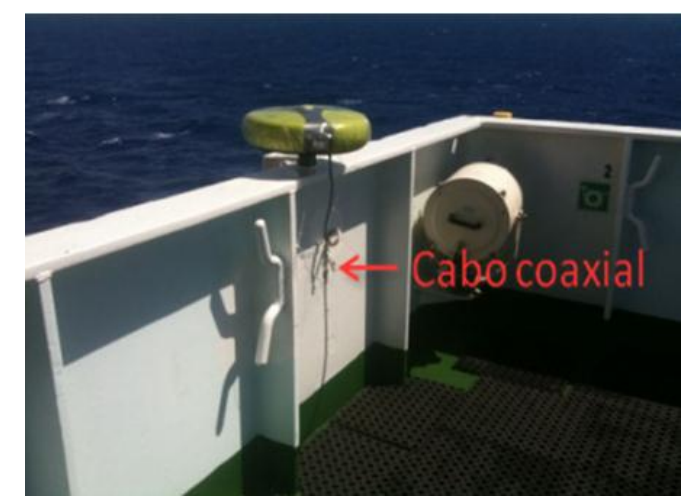

Figura 5: Antena do receptor GPS instalada sobre o guarda-corpo

As ligações das antenas, apresentada na Figura 5, aos receptores foram realizadas através de cabos coaxiais blindados com 10 metros de comprimento seguindo a especificação do fabricante. Para evitar a oxidação dos terminais durante a viagem, e por conseqüência a geração de correntes de fuga, estes foram revestidos por fita isolante emborrachada, do tipo usado para instalações de alta-tensão. Para evitar a movimentação rotacional da antena cabos de nylon foram estirados entre as argolas de fixação na base da antena e ressaltos na estrutura metálica do guarda corpo. Tais amarrações tinham como objetivo evitar o desprendimento da antena por eventual rotação causada acidentalmente por algum operador ou pelo vento.

Os receptores utilizados nesta instalação possuem memória interna não removível e não expansível de 32MB. Estas características fazem com que os dados sejam transferidos da memória interna para um computador somente por meio da porta serial e um cabo com conectores de 9 pinos padrão RS-232 fornecido pelo fabricante com o equipamento. Para esta transferência deve ser utilizado um computador portátil com comunicação serial ou adaptador equivalente.

\subsubsection{Percurso}

O percurso realizado para o levantamento das observáveis GPS foi a partir do porto de Santos (SP) até o porto de Suape (PE) com escala no porto de Sepetiba (RJ). A embarcação iniciou a viagem no dia 26/07/2011 às $21 \mathrm{~h} 13 \mathrm{~min} 30$ s (UTC). O comprimento do trajeto realizado obtido pelo GPS1 foi de $2414,93 \mathrm{~km}$ e de $2414,52 \mathrm{~km}$ para o GPS2.

Este trajeto foi dividido em três trechos principais: Santos-Sepetiba, Sepetiba-Suape(fundeado), Suape(fundeado)-Suape(atracado). Tal divisão foi consequência do desligamento dos receptores devido a embarcação ter ficado parada por mais de uma hora, o que consumiria espaço na memória com registros desnecessários. Ao religar os equipamentos são gerados novos arquivos de rastreio de forma automática. A Tabela 5 apresenta as principais informações obtidas ao longo da viagem.

O trecho entre Sepetiba-Suape(fundeado) foi sub-dividido em quatro partes devido a uma restrição no pós-processamento dos dados pelo IBGE, na qual o arquivo padrão Rinex gerado pelo rastreio não pode ser maior que 20MB. A Tabela 6 apresenta as informações do trecho Sepetiba-Suape(fundeado) e suas quatro divisões. 
Tabela 5: Principais informações obtidas ao longo do percurso

\begin{tabular}{|c|c|c|c|c|c|c|}
\hline & \multicolumn{2}{|c|}{ Santos - Sepetiba } & \multicolumn{2}{|c|}{$\begin{array}{c}\text { Sepetiba-Suape } \\
\text { (fundeado) }\end{array}$} & \multicolumn{2}{|c|}{$\begin{array}{c}\text { Suape } \\
\text { (fundeado-porto) }\end{array}$} \\
\hline \multirow{3}{*}{ Início (UTC) } & GPS1 & GPS2 & GPS1 & GPS2 & GPS1 & GPS2 \\
\hline & $26 / 07 / 11$ & $26 / 07 / 11$ & $28 / 07 / 11$ & $28 / 07 / 11$ & $31 / 07 / 11$ & $31 / 07 / 11$ \\
\hline & $20: 01: 30$ & $20: 02: 20$ & $06: 08: 50$ & $06: 07: 50$ & $18: 57: 40$ & $19: 01: 00$ \\
\hline \multirow{2}{*}{ Fim(UTC) } & $27 / 07 / 11$ & $27 / 07 / 11$ & $31 / 07 / 11$ & $31 / 07 / 11$ & $31 / 07 / 11$ & $31 / 07 / 11$ \\
\hline & $15: 34: 20$ & $15: 32: 20$ & $11: 21: 20$ & $11: 20: 50$ & $22: 20: 40$ & $22: 08: 50$ \\
\hline Tempo de rastreio & $19: 32: 50$ & $19: 30: 00$ & $77: 12: 30$ & $77: 13: 00$ & $03: 23: 00$ & $03: 07: 50$ \\
\hline Comprimento(km) & 323,351 & 323,166 & 2080,187 & 2080,084 & 11,395 & 11,279 \\
\hline Veloc. média $(\mathrm{km} / \mathrm{h})$ & 16,582 & 16,572 & 26,947 & 26,945 & 3,640 & 3,603 \\
\hline
\end{tabular}

Tabela 6: Informações dos trechos entre Sepetiba-Suape(fundeado)

\begin{tabular}{|c|c|c|c|c|c|c|c|c|}
\hline & \multicolumn{2}{|c|}{ Trecho 1} & \multicolumn{2}{|c|}{ Trecho 2} & \multicolumn{2}{|c|}{ Trecho 3} & \multicolumn{2}{|c|}{ Trecho 4} \\
\hline & GPS1 & GPS2 & GPS1 & GPS2 & GPS1 & GPS2 & GPS1 & GPS2 \\
\hline \multirow{2}{*}{ Início (UTC) } & $28 / 07 / 11$ & $28 / 07 / 11$ & $29 / 07 / 11$ & $29 / 07 / 11$ & $30 / 07 / 11$ & $30 / 07 / 11$ & $31 / 07 / 11$ & $31 / 07 / 11$ \\
\hline & $06: 08: 50$ & $06: 07: 50$ & 00:00:00 & 00:00:00 & 00:00:00 & 00:00:00 & 00:00:00 & 00:00:00 \\
\hline \multirow{2}{*}{ Fim (UTC) } & $28 / 07 / 11$ & $28 / 07 / 11$ & $29 / 07 / 11$ & $29 / 07 / 11$ & $30 / 07 / 11$ & $30 / 07 / 11$ & $31 / 07 / 11$ & $31 / 07 / 11$ \\
\hline & $23: 59: 50$ & $23: 59: 50$ & $23: 59: 50$ & $23: 59: 50$ & $23: 59: 50$ & $23: 59: 50$ & $11: 21: 20$ & $11: 20: 50$ \\
\hline Tempo de $\mathrm{r}$ & $17: 51: 00$ & $17: 52: 00$ & $23: 59: 50$ & $23: 59: 50$ & $23: 59: 50$ & $23: 59: 50$ & $11: 21: 20$ & $11: 20: 50$ \\
\hline Comprimento $(\mathrm{km})$ & 447,390 & 447,276 & 655,332 & 655,331 & 676,540 & 676,539 & 300,610 & 300,632 \\
\hline Veloc. média $(\mathrm{km} / \mathrm{h})$ & 25,070 & 25,064 & 27,309 & 27,309 & 28,196 & 28,195 & 26,492 & 26,494 \\
\hline
\end{tabular}

\subsubsection{Dados GPS}

Para o rastreamento dinâmico do navio, o receptor foi configurado para registrar as observáveis GPS a cada intervalo de tempo de 10s. Os intervalos de registros foram assim configurados considerando-se o espaço de memória interna do aparelho, de modo que todo o percurso pudesse ser registrado sem a obrigatoriedade de transferi-los para o computador portátil, o que em uma embarcação sob condições meteorológicas adversas pode ser tecnicamente muito difícil.

\subsection{Metodologia}

\subsubsection{Processamento dos dados GPS}

Os dados rastreados por ambos os receptores foram transferidos para um computador portátil pela porta de comunicação de dados padrão serial RS-232 através de um software próprio fornecido pelo fabricante. Em seguida, foram gravados os dados em um formato proprietário, porém facilmente transformado para o formato aberto Rinex versão 2.11. A restrição imposta pelo sistema de pós-processamento oferecido pelo IBGE (2015), na qual os arquivos não podem ultrapassar o tamanho em disco de 20MB, fez com que eles fossem divididos em arquivos menores. Para isso, os cabeçalhos dos arquivos foram reconstruídos em um editor de textos seguindo os padrões do formato em questão. Estes arquivos foram, então, enviados para o sítio Internet do IBGE (2015). Após o processamento, os arquivos com as séries históricas das 
coordenadas foram enviados para um endereço de email especificado durante o processo de envio. Para cada arquivo Rinex enviado foram recebidos cinco arquivos com as seguintes informações (IBGE, 2014):

Resumo do relatório em PDF, onde são apresentados os detalhes do processamento como erros e problemas no arquivo enviado; Relatório com o resultado, o qual contém as coordenadas geodésicas do processamento estático; Arquivo com as coordenadas geodésicas ao longo do tempo, resultado do processamento cinemático; Arquivo padrão KML (2011) do software GOOGLEARTH 6.0 (2014) que indica o local aproximado do rastreio, caso se opte pelo processamento estático ou que apresenta as coordenadas geodésicas do trajeto percorrido, caso opte por processamento cinemático; e o arquivo TXT com a descrição dos arquivos recebidos.

Assim, o arquivo com as posições ao longo do tempo, resultado do processamento cinemático, foi o utilizado neste trabalho para obtenção das coordenadas geográficas do trajeto realizado.

\subsubsection{Estimativa da Precisão}

No posicionamento por GPS, vários fatores podem degradar a acurácia das coordenadas obtidas. A precisão do posicionamento dos satélites na órbita, os atrasos e os desvios na trajetória sofridos na propagação através da atmosfera do sinal do satélite ao receptor são as principais incertezas aleatórias incidentes no processo de obtenção da posição. Podemos considerar, ainda, como fator de degradação do sinal o efeito denominado multicaminhamento, no qual os diferentes caminhos percorridos entre o sinal direto e o refletido por alguma superfície refletora próxima à antena causam distorções na recepção.

Para a estimativa da precisão obtida nas coordenadas ao longo do percurso foram adotadas duas soluções. A primeira foi estimada a partir do resíduo do ajustamento das amostras superabundantes das distâncias do receptor ao satélite. Estas estimativas são fornecidas pelo processamento PPP oferecido pelo IBGE e disponibilizadas no mesmo arquivo das coordenadas. A segunda foi estimada como sendo o desvio padrão das variações na distância entre os receptores. Partindo-se do pressuposto que ambos os receptores estavam solidamente fixados à estrutura metálica do passadiço, assumida a princípio como inelástica, a variação da distância obtida pelo posicionamento GPS deveria ser zero. Assim, foram calculadas as distâncias entre as coordenadas geográficas dos dois receptores à mesma época e o desvio padrão foi estimado para a amostragem obtida.

\subsubsection{Comparação entre os deslocamentos dos receptores}

A correlação entre as direções de deslocamento das antenas obtida durante o percurso pode ser usada como um parâmetro associado à qualidade das informações do rastreio, no sentido em que, se os deslocamentos obtidos estão próximos em valor e direção, os receptores estão registrando os deslocamentos de forma coerente entre si. Vale notar que este parâmetro é afetado em condições de baixa velocidade como em manobras de atracação da embarcação, quando 
movimentos de rotação e deriva provocados pelos barcos rebocadores são contínuos e as direções das antenas, nestas condições, são muito diferentes entre si.

Para a obtenção da medida de correlação entre as informações rastreadas por cada receptor, as coordenadas geodésicas das séries históricas foram transformadas em coordenadas UTM e, em seguida, calculados os azimutes dos deslocamentos subsequentes, considerando-se a coordenada atual e a imediatamente anterior. Em seguida, foram calculados os coeficientes de correlação de Pearson $(R)$ dos deslocamentos sucessivos sofridos em cada antena, apresentados no gráfico de espalhamento na Figura 6. O coeficiente $R^{2}$ é usado para designar quão bem os dados se ajustam à reta de regressão e, por consequência, mensurar a correlação entre as duas fontes de dados. A Equação 1 apresenta como foi calculado o coeficiente de Pearson neste trabalho:

$$
R=\frac{\sum_{i=1}^{n}\left(x_{i}-\bar{x}\right)\left(y_{i}-\bar{y}\right)}{\sqrt{\sum_{i=1}^{n}\left(x_{i}-\bar{x}\right)^{2}} \cdot \sqrt{\sum_{i=1}^{n}\left(y_{i}-\bar{y}\right)^{2}}}
$$

onde:

$x_{i}$ e $y_{i}$ são os valores dos azimutes do GPS1 e GPS2 na época $i$;

$\bar{x}$ e $\bar{y}$ são os valores médios de $x$ e $y$ respectivamente.

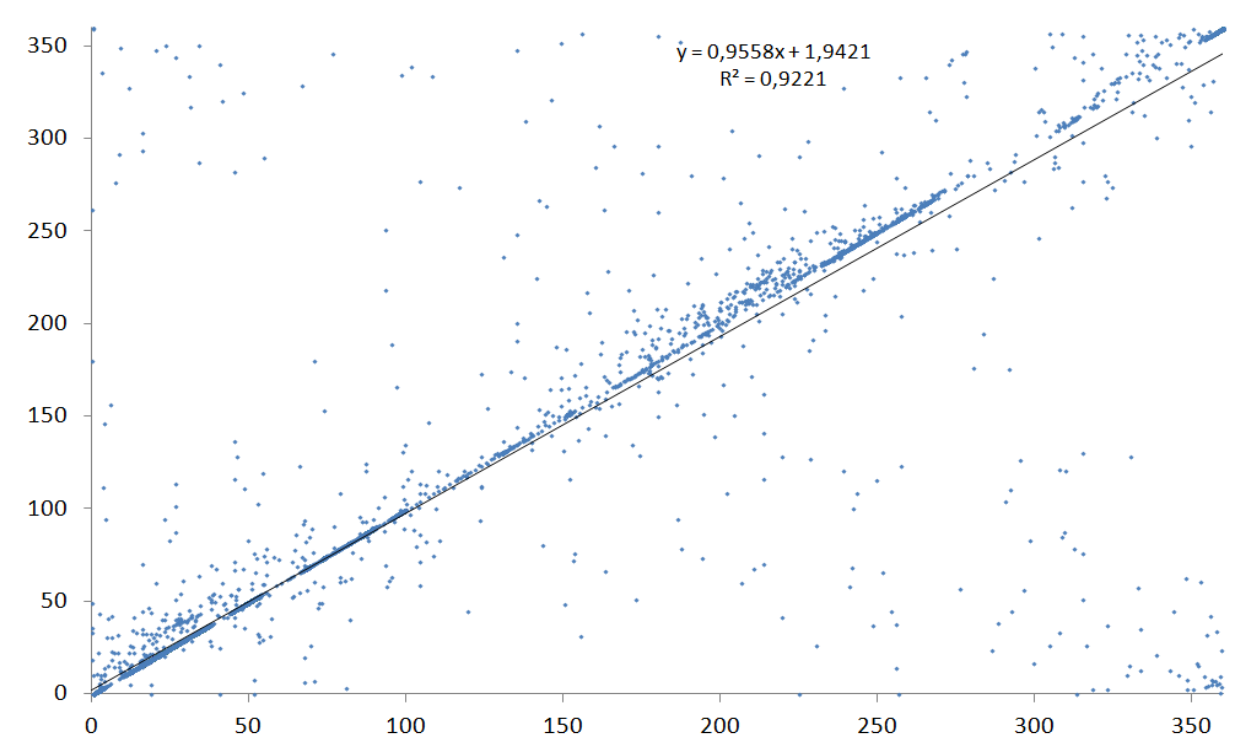

Figura 6: Espalhamento dos valores do Azimute (em graus) do GPS1 (eixo $x$ ) vs. GPS2 (eixo

y) para o percurso realizado; e respectivo coeficiente de correlação $R^{2}$

\section{Resultados e discussões}

\subsection{Precisão}

O sistema de pós-processamento estima a precisão nas coordenadas a partir de resíduos encontrados no cálculo de ajustamento das distâncias dos satélites às antenas. $\mathrm{O}$ cálculo destes 
resíduos é discutido em AIUB (2007). Para este trabalho a precisão média estimada ( $\sigma \mathrm{GPS})$ para o percurso foi de $\sim 11,4 \mathrm{~cm}$, conforme apresentado nas Tabelas 7 e 8 .

Devido a existência da sala de comando no passadiço, entre as antenas receptoras instaladas, não foi possível fazer uma medida acurada da distância entre as antenas. Esta medida permitiria avaliar a acurácia, e não somente a precisão, das medidas obtidas pelos receptores. Assim, foi assumido o desvio padrão da distância observada entre as antenas como uma estimativa da precisão média alcançada. Neste levantamento, obteve-se aproximadamente $23,1 \mathrm{~cm}$ de precisão para todo o percurso e tempo de rastreio. Desprezando os primeiros 60 minutos de dados do arquivo Rinex a precisão obtida foi de $\sim 8,0 \mathrm{~cm}$. Desprezado os primeiros 120 minutos dos arquivos, a precisão obtida foi de $\sim 7,4 \mathrm{~cm}$. Assim, a precisão tem uma melhora significativa quando eliminado a partir dos primeiros 30 minutos dos rastreio e melhorando relativamente muito pouco para intervalos maiores, conforme apresentado na Figura 7. Portanto, a precisão obtida no posicionamento pode ser melhor que a estimativa de resíduos do sistema de pósprocessamento, dependendo do critério de corte aplicado ao início dos arquivos de dados, como apresentado na Figura 8.

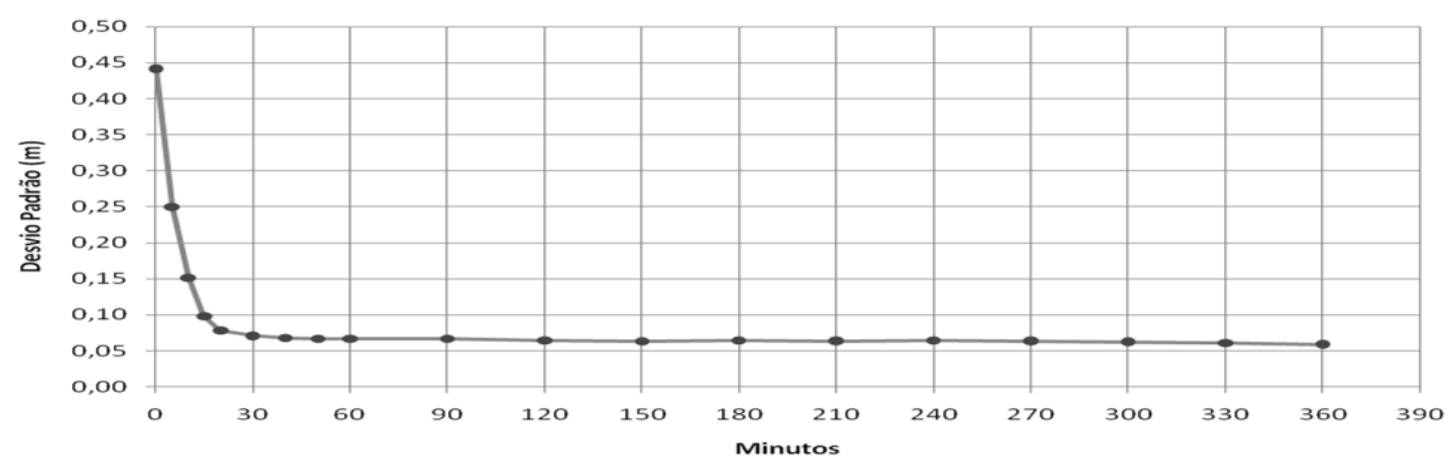

Figura 7: Desvio padrão das distâncias entre as antenas

Tabela 7: Precisão obtida para o trajeto total

\begin{tabular}{|c|c|c|c|c|c|c|}
\hline & \multicolumn{2}{|c|}{ Santos - Sepetiba } & \multicolumn{2}{|c|}{ Sepetiba-Suape (fundeado) } & \multicolumn{2}{|c|}{ Suape (fundeado-porto) } \\
\hline & GPS1 & GPS2 & GPS1 & GPS2 & GPS1 & GPS2 \\
\hline Início (UTC) & $26 / 07 / 11$ & $26 / 07 / 11$ & $\begin{array}{l}28 / 07 / 11 \\
06 \cdot 08 \cdot 50\end{array}$ & $\begin{array}{l}28 / 07 / 11 \\
06 \cdot 07 \cdot 50\end{array}$ & $\begin{array}{l}31 / 07 / 11 \\
18 \cdot 57 \cdot 40\end{array}$ & $31 / 07 / 11$ \\
\hline Fim (UTC) & $\begin{array}{l}27 / 07 / 11 \\
15: 34: 20\end{array}$ & $\begin{array}{l}27 / 07 / 11 \\
15: 32: 20\end{array}$ & $\begin{array}{l}31 / 07 / 11 \\
11: 21: 20\end{array}$ & $\begin{array}{l}31 / 07 / 11 \\
11: 20: 50\end{array}$ & $\begin{array}{l}31 / 07 / 11 \\
22: 20: 40\end{array}$ & $\begin{array}{l}31 / 07 / 11 \\
22: 08: 50\end{array}$ \\
\hline Tempo de rastreio & $19: 32: 50$ & $19: 30: 00$ & $77: 12: 30$ & $77: 13: 00$ & 03:23:00 & 03:07:50 \\
\hline бLatitude (cm) & 3,77 & 3,16 & 3,12 & 3,01 & 3,91 & 4,07 \\
\hline бLongitude (cm) & 3,48 & 3,17 & 3,47 & 3,52 & 5,30 & 5,15 \\
\hline$\sigma$ Altitude $(\mathrm{cm})$ & 9,38 & 8,24 & 9,77 & 9,45 & 11,77 & 11,90 \\
\hline$\sigma$ Total GPS (cm) & \multicolumn{2}{|c|}{10,03} & \multicolumn{2}{|c|}{10,67} & \multicolumn{2}{|c|}{13,54} \\
\hline $\begin{array}{l}\text { Distância entre } \\
\text { antenas (m) }\end{array}$ & \multicolumn{2}{|c|}{29,10} & \multicolumn{2}{|c|}{29,14} & \multicolumn{2}{|c|}{29,10} \\
\hline $\begin{array}{l}\text { Desvio padrão } \\
(0 \mathrm{~min})\end{array}$ & \multicolumn{2}{|c|}{44,18} & \multicolumn{2}{|c|}{14,06} & \multicolumn{2}{|c|}{11,06} \\
\hline$(60 \mathrm{~min})$ & \multicolumn{2}{|c|}{6,66} & \multicolumn{2}{|c|}{13,38} & \multicolumn{2}{|c|}{4,13} \\
\hline$(120 \mathrm{~min})$ & \multicolumn{2}{|c|}{6,48} & \multicolumn{2}{|c|}{11,99} & \multicolumn{2}{|c|}{3,77} \\
\hline
\end{tabular}


Tabela 8: Precisão obtida para Sepetiba-Suape(fundeado) por trecho

\begin{tabular}{|c|c|c|c|c|c|c|c|c|}
\hline & \multicolumn{2}{|c|}{ Trecho 1} & \multicolumn{2}{|c|}{ Trecho 2} & \multicolumn{2}{|c|}{ Trecho 3} & \multicolumn{2}{|c|}{ Trecho 4} \\
\hline & GPS1 & GPS2 & GPS1 & GPS2 & GPS1 & GPS2 & GPS1 & GPS2 \\
\hline \multirow{2}{*}{ Início (UTC) } & $28 / 07 / 11$ & $28 / 07 / 11$ & $29 / 07 / 11$ & $29 / 07 / 11$ & $30 / 07 / 11$ & $30 / 07 / 11$ & $31 / 07 / 11$ & $31 / 07 / 11$ \\
\hline & 06:08:50 & 06:07:50 & 00:00:00 & 00:00:00 & $00: 00: 00$ & 00:00:00 & $00: 00: 00$ & 00:00:00 \\
\hline \multirow{2}{*}{ Fim (UTC) } & 28/07/11 & 28/07/11 & 29/07/11 & 29/07/11 & $30 / 07 / 11$ & $30 / 07 / 11$ & $31 / 07 / 11$ & $31 / 07 / 11$ \\
\hline & $23: 59: 50$ & $23: 59: 50$ & 23:59:50 & $23: 59: 50$ & 23:59:50 & $23: 59: 50$ & $11: 21: 20$ & $11: 20: 50$ \\
\hline Tempo de rastreio & $17: 51: 00$ & $17: 52: 00$ & $23: 59: 50$ & $23: 59: 50$ & 23:59:50 & $23: 59: 50$ & $11: 21: 20$ & $11: 20: 50$ \\
\hline бLatitude (cm) & 3,52 & 3,36 & 3,10 & 3,02 & 2,81 & 2,80 & 3,21 & 2,86 \\
\hline бLongitude (cm) & 3,55 & 4,04 & 3,40 & 3,21 & 3,42 & 3,33 & 3,56 & 3,73 \\
\hline бAltitude $(\mathrm{cm})$ & 8,31 & 8,19 & 9,82 & 9,58 & 9,93 & 9,80 & 11,61 & 10,40 \\
\hline$\sigma$ Total GPS $(\mathrm{cm})$ & \multicolumn{2}{|c|}{9,71} & \multicolumn{2}{|c|}{10,70} & \multicolumn{2}{|c|}{10,80} & \multicolumn{2}{|c|}{11,99} \\
\hline $\begin{array}{l}\text { Distância entre } \\
\text { antenas (m) }\end{array}$ & \multirow{2}{*}{\multicolumn{2}{|c|}{29,13}} & \multirow{2}{*}{\multicolumn{2}{|c|}{29,12}} & \multirow{2}{*}{\multicolumn{2}{|c|}{29,15}} & \multirow{2}{*}{\multicolumn{2}{|c|}{29,20}} \\
\hline Desvio padrão & & & & & & & & \\
\hline$(0 \mathrm{~min})$ & \multicolumn{2}{|c|}{16,72} & \multicolumn{2}{|c|}{14,42} & \multicolumn{2}{|c|}{10,60} & \multicolumn{2}{|c|}{13,03} \\
\hline$(60 \mathrm{~min})$ & \multicolumn{2}{|c|}{13,97} & \multicolumn{2}{|c|}{9,46} & \multicolumn{2}{|c|}{6,00} & \multicolumn{2}{|c|}{6,49} \\
\hline$(120 \mathrm{~min})$ & \multicolumn{2}{|c|}{5,97} & \multicolumn{2}{|c|}{9,46} & \multicolumn{2}{|c|}{5,15} & \multicolumn{2}{|c|}{5,18} \\
\hline
\end{tabular}

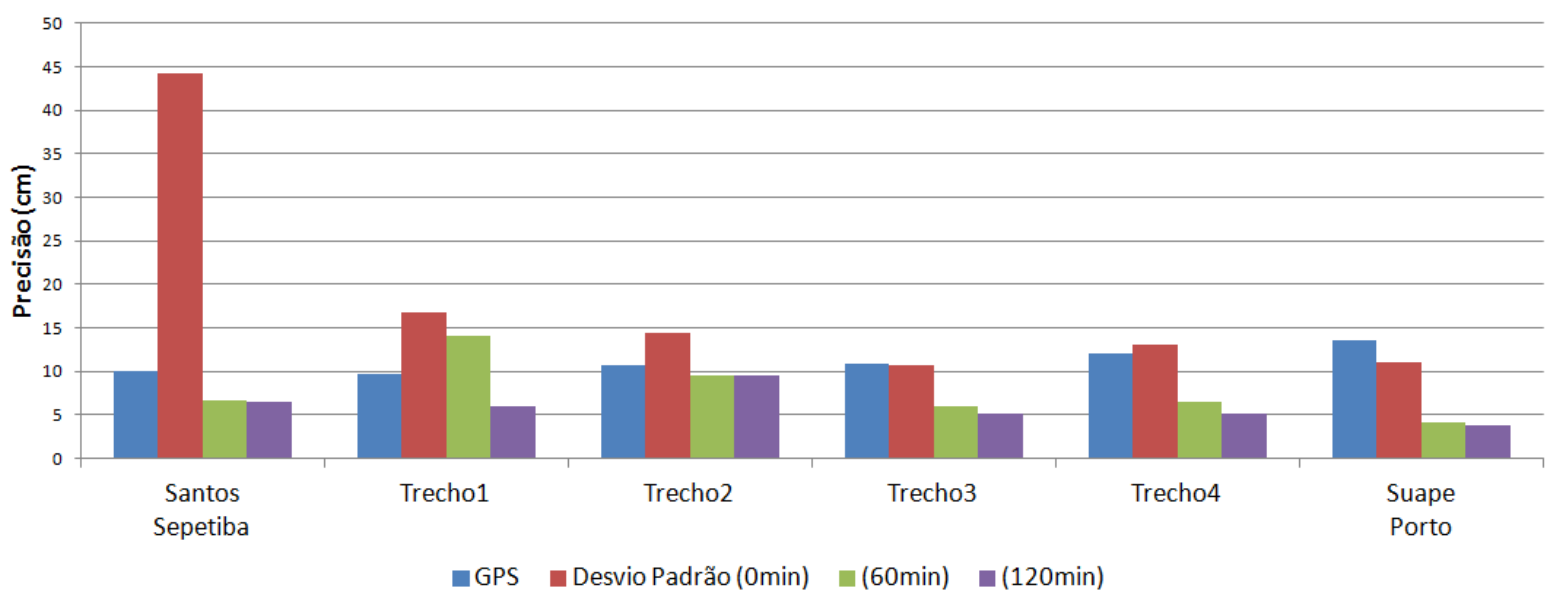

Figura 8: Precisão obtida para os diferentes trechos percorridos estimada pelo pósprocessamento GPS ( $1^{\text {a }}$ coluna dos grupos) e pelo desvio padrão das distâncias das antenas utilizando diferentes tempos de corte: $0 \mathrm{~min}, 60 \mathrm{~min}$ e $120 \mathrm{~min}$.

\subsection{Correlação entre os azimutes}

Analisando-se o histograma da distribuição da freqüência das velocidades da embarcação durante a realização do trajeto, na Figura 9, pode-se observar um pico da imobilidade até $3 \mathrm{~km} / \mathrm{h}$, relativo às manobras em baixas velocidades; e um segundo pico em velocidades acima de 27 $\mathrm{km} / \mathrm{h}$, quando então ocorrem os deslocamentos mais longos e por maior intervalo de tempo. A coerência encontrada para todo o percurso, considerando as referidas manobras foi $R^{2}=0,922$, o que pode ser considerada como um valor alto. 


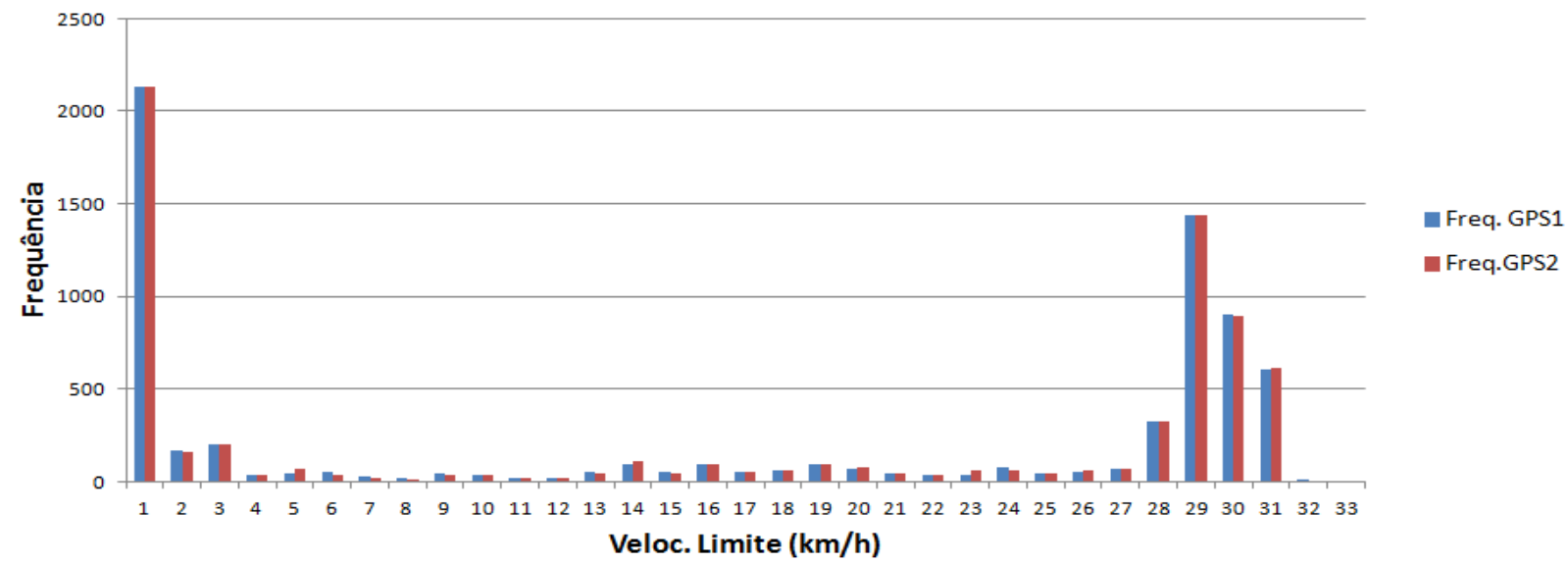

Figura 9: Histograma da distribuição das frequências das amostras em função das velocidades de deslocamento

\section{Conclusões}

Neste estudo foi apresentada uma alternativa de instrumentação para a obtenção de coordenadas precisas de embarcações de grande porte em alto mar usando a tecnologia de posicionamento através de satélites artificiais da constelação GPS. As características da instalação e pósprocessamento dos dados são apresentadas de forma a proporcionar uma solução técnica viável sob o ponto de vista das adversas condições ambientais.

A precisão média no posicionamento ( $\sigma$ GPS) para o percurso foi de $\sim 11,4 \mathrm{~cm}$ e o desvio padrão na distância entre as antenas foi de 23,1 cm. Desprezando-se os primeiros 60 e 120 minutos de rastreio, esta precisão na distância melhora para $\sim 8,0 \mathrm{~cm} \mathrm{e} \sim 7,4 \mathrm{~cm}$ respectivamente. A correlação entre as direções percorridas por cada antena dos receptores foi de $R^{2}=0,922$. Esses resultados permitem que as grandezas físicas derivadas possam ser usadas futuramente como parâmetros de calibração de modelos de estimativa de consumo instantâneo de combustível e emissão dos gases causadores do efeito estufa (GEE), a partir da variação energética instantânea do deslocamento.

Vale ressaltar que, devido à característica do PPP cinemático pós-processado, existe a necessidade de se ligar os receptores e iniciar o rastreamento com no mínimo 30 minutos de antecedência ao movimento da embarcação a ser monitorada. Havendo a disponibilidade de memória e carga da bateria é recomendável iniciar estas atividades 1 hora antes. Essas esperas poderão ser reduzidas com a disponibilização no futuro do PPP em tempo real.

\section{AGRADECIMENTOS}

Este estudo foi parcialmente financiado pela Coordenação de Aperfeiçoamento de Pessoal de Nível Superior (CAPES), através do Programa Nacional de Pós Doutorado (PNPD), e pelo Conselho Nacional de Desenvolvimento Científico e Tecnológico (CNPq), processo 
402401/2009-3. Os autores agradecem o apoio das empresas parceiras do CISLog - Poli-USP e do laboratório de Topografia e Geodésia (LTG) - Poli-USP pelo auxílio com os instrumentos.

\section{REFERÊNCIAS BIBLIOGRÁFICAS}

AIUB. 2007. "User manual of the Bernese GPS Software Version 5.0", Astronomical Institute of University of Bern, last modification 2007, accessed September 25, 2015, http://www.bernese.unibe.ch/docs50/DOCU50.pdf.

ANTAQ. Agência Nacional de Transportes Aquaviários. 2011, accessed September 25, 2015, http://www.syndarma.org.br/upload/Estatistica\%20de\%20navega_o\%20maritima\%20brasileira $\% 202010 . p d f$.

Cintra, J. P.; M. A. Nero and Rodrigues, D., "GNSS/NTRIP Service and technique: accuracy tests". Boletim de Ciências Geodésicas Online, (2011): 257-271, v. 17, ISSN 1982-2170

CNT. Confederação Nacional dos Transportes. 2015. "Plano CNT de Transporte e Logística 2011", accessed December 2011,

http://www.cnt.org.br/Imagens\%20CNT/PDFs\%20CNT/Plano\%20CNT\%20de\%20Log\%C3\%A Dstica/PlanoCNTdeLog2011.pdf, visitado em 25/09/2015.

Demir, E., Bektaş, T., and Laporte, G. "A comparative analysis of several vehicle emission models for road freight transportation", Transportation Research Part D: Transport and Environment, (2011): 347-357, v. 16, n. 5, ISSN 1361-9209, 10.1016.

Ebner, R., and Featherstone, W. E. "How well can online GPS PPP post-processing services can be used to establish geodetic survey control networks?", Journal of Applied Geodesy 2, (2008): 149-157. doi 10.1515/JAG.2008.017.

Geng, J., Teferle, F.N., Meng, X., and Dodson, A.H.. "Kinematic Precise Point Positioning at Remote Marine Platforms", GPS-Solutions - The Journal of Global Navigation Satellite Systems, (2010): 343-350, v. 14, doi 10.1007/s 10291-009-0157-9.

Googleearth 6.0. 2014. Accessed July 8, 2014. http://earth.google.com/intl/pt-BR/.

IBGE. Instituto Brasileiro de Geografia e Estatística. 2014. "Manual do Usuário Posicionamento Por Ponto Preciso PPP" Accessed July 8, 2014.

http://www.ibge.gov.br/home/geociencias/geodesia/ppp/manual_ppp.pdf.

IBGE. Instituto Brasileiro de Geografia e Estatística 2015. "Posicionamento por Ponto Preciso (PPP)" Accessed September 25, 2015. http://www.ppp.ibge.gov.br/ppp.htm.

IGS. "International GNSS Service". 2012 Accessed May 4, 2012.

http://igs.org/components/prods.html.

KML. "Keyhole Markup Language". 2011. Accessed July 8, 2011.

http://code.google.com/intl/pt-BR/apis/kml/documentation/.

Kouba, J. and Héroux, P. "GPS Precise Point Positioning Using IGS Orbit Products", Physics and Chemistry of the Earth Part A Solid Earth and Geodesy, (2001): p. 573-578, v. 26, n. 6-8, doi: 10.1016/S1464-1895(01)00103-X. 
Moore, A. M. and Neilan, R. E. "The International GPS Service tracking network: enabling diverse studies and projects through international cooperation", Journal of Geodynamics, (2005): 461-469n. 40 v. 4-5.

NRCan. "Geodetic Survey Division of Natural Resources of Canada". 2015. Accessed September 9, 2015. http://www.geod.nrcan.gc.ca/products-produits/ppp_e.php.

RBMC. "Rede Brasileira de Monitoramento Contínuo dos Sistemas GNSS". 2015. Instituto Brasileiro de Geografia e Estatística - IBGE. Accessed September 9, 2015. http://www.ibge.gov.br/home/geociencias/geodesia/rbmc/rbmc.shtm.

Zumberge, J. F., Heftin, M. B., Jefferson, D.C., Watkins, M. M., and Webb, F. H. "Precise point positioning for the efficient and robust analysis of GPS data from large networks", Journal of Geophysical Research, (1997): 5005-5017, v. 102, n. B3.

Recebido em Novembro de 2015.

Aceito em Janeiro de 2016. 